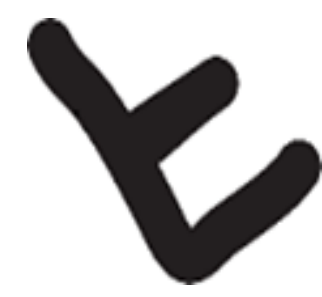

REVISTA DE ESTUDIOS E INVESTIGACIÓN EN PSICOLOGÍA Y EDUCACIÓN

ISSN: 1138-1663; eISSN: 2386-7418

2020, Vol. 7, No. 2, 194-196.

DOI: https://doi.org/10.17979/reipe.2020.7.2.7068

\title{
Reseña del libro: Educación artística sensible. Cartografía contemporánea para arteducadores
}

Book review: Sensitive art education. Contemporary cartography for art educators

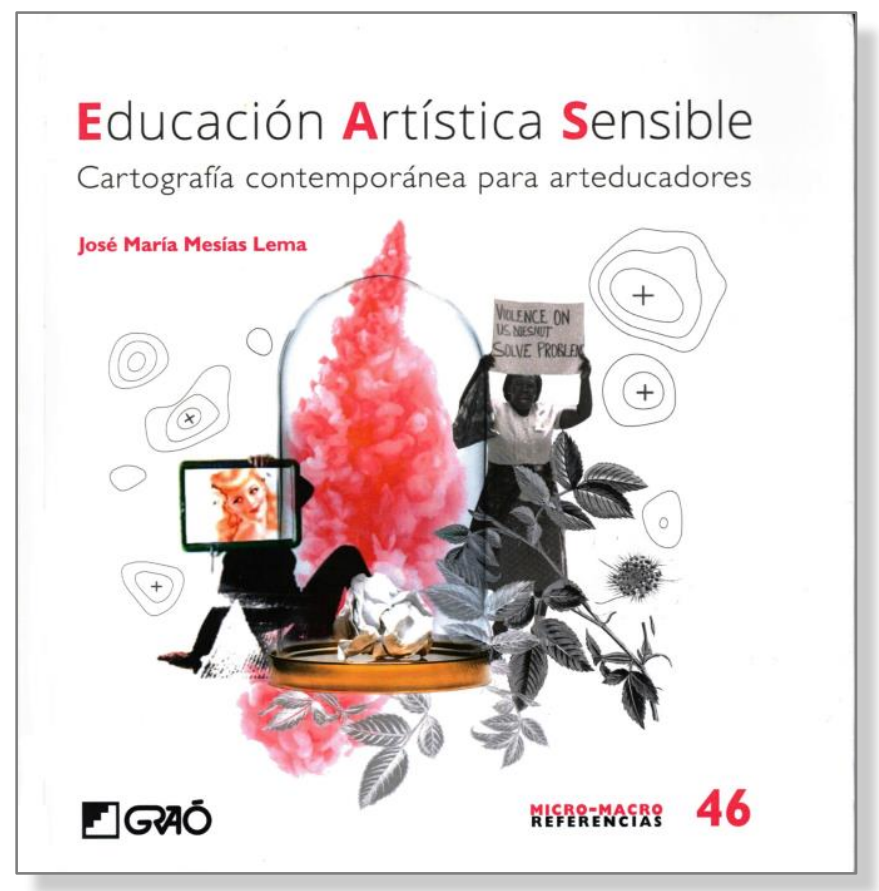

Autor: José María Mesías-Lema

Facultad de Ciencias de la Educación, Universidade da Coruña, España.

Editorial: Graó

Lugar de edición: Barcelona, España

Número de páginas: 221

Año: 2019

ISBN: 978-84-9980-984-7

Depósito legal: B-15940-2019

Este libro es un objeto artístico que critica contundentemente la situación de la Educación Artística actual, aportando una visión innovadora para el cambio a través de la experiencia de quince años del joven autor. Su planteamiento es sensible, intuitivo, arriesgado y transgresor a la hora de plantear ideas y críticas constructivas, y así lo muestran también su formato, imagen y estructura.

La obra consiste en una investigación rigurosa en la que el autor comparte numerosos proyectos comisariales - desde los primeros en el CGAC (Agra y Mesías, 2007) y en el MACUF (Mesías-Lema, 2011)- 
que muestran la enseñanza-aprendizaje de las artes. Conectado con el panorama actual, hace una crítica al sistema neoliberal que entiende el arte de manera elitista a través de jerarquías; ese sistema político que regula el currículum educativo reduccionista y excluyente con el que contamos.

Plantea, entonces, la necesidad de una enseñanza artística entendida como un laboratorio experimental en la formación docente (Mesías-Lema, 2017), acorde a las necesidades y exigencias reales de nuestra sociedad actual. Una Educación Artística más humana, estética y divergente, que permita a los alumnos pensar por sí mismos. Y es que la escuela no puede limitarse única y exclusivamente al desarrollo competencial y de contenidos descontextualizados de la vida del alumnado.

Contar con una formación estética y sensible resulta fundamental para alcanzar un desarrollo integral como personas. De hecho, el autor cita numerosos estudios de neuroestética que muestran una relación directa entre la capacidad intelectual y la artística; entendiendo, por tanto, que excluyendo alguna de las dos estaríamos ante un modelo incompleto e inadecuado. "Educación artística sensible" alude, precisamente, a ese tratamiento de lo artístico desde la mirada sensible y estética que nos humaniza. Este planteamiento reivindica una transformación real de la didáctica de las artes, modificando su planteamiento obsoleto.

Urge evolucionar hacia modelos contemporáneos, contextualizados y participativos, en donde se generen estrategias sensibles para la provocación de aprendizajes y proyectos educativos en contacto con la comunidad. La clave para conseguirlo, dice el autor, está en subvertir los roles y el propio concepto de aula; logrando que el placer, la participación y la transgresión ocupen el espacio y permitiendo el fracaso, la pedagogía de tiempos pausados y la creación artística contemporánea. A estos docentes que se atreven a romper con los moldes, Mesías los denomina "arteducadores".

Los "arteducadores" son docentes comprometidos con la Educación Artística de una manera sensible al contexto contemporáneo. "Outsiders al sistema" que buscan transformar el entorno que les rodea y no atienden a imposiciones curriculares. Sacan a la luz lo oculto, identificando y exponiendo realidades que no interesa hacer públicas, y trabajan para combatir las injusticias y generar el cambio desde la colaboración y lo colectivo.

Esta capacidad de percibir el mundo de otro modo, hace de la sensibilidad una fortaleza, y la aleja de la debilidad con la que se la relaciona frecuentemente. Se asocia este término con estados de ánimo como la tristeza o la melancolía e incluso como un signo de fragilidad; sin embargo, insiste el autor en que la sensibilidad es una cualidad que nos permite analizar el mundo de un modo más profundo y ver lo que habitualmente pasa desapercibido.

Somos curiosos, creativos y críticos por naturaleza, pero esa capacidad para cuestionarlo todo con la que nacemos se va perdiendo conforme nos hacemos adultos. Lo mismo sucede con la relación con el arte: los niños y niñas se acercan sin prejuicio a las obras contemporáneas de una manera mucho más profunda que los mayores. Casi con total seguridad, una de las causas principales de que suceda esto es el modelo educativo que estamos ofreciendo a nuestro alumnado; ese que, como ya hemos dicho, ha dejado la formación sensible y artística a un lado para centrarse únicamente en el plano intelectual.

El arte contemporáneo pretende cuestionar y que nos cuestionemos, que miremos más allá y que rompamos con lo establecido para dar paso a lo nuevo. Por esta razón, posiblemente, las políticas educativas han relegado la Educación Artística a un segundo plano, porque supone una amenaza para el sistema, lo normativo, lo hegemónico y lo impuesto.

Es probable que sea esta una de las causas de que existan tantos prejuicios relacionados con el arte. Apreciamos el arte por su supuesta calidad técnica y por su parecido con la realidad y rechazamos todo aquello que no somos capaces de entender, algo que -como dice el autor- no sucede en la infancia. Desde el punto de vista de Mesías, el arte contemporáneo exige un análisis más profundo y riguroso. El concepto de estética es un concepto mutante que precisa de un conocimiento previo y una mirada crítica a través de la que analizar lo que vemos, asegura. De ahí la importancia una vez más de la formación del alumnado y profesorado en Educación Artística sensible.

Difícilmente podemos enseñar a aprender arte en educación si no deconstruimos los prejuicios y estereotipos asociados que el autor analiza y desarrolla a lo largo de su obra. Los estudiantes deben aprender 
a enfrentarse al error y a la frustración, cuestiones no permitidas en la educación tradicional y que resultan fundamentales para el aprendizaje y para la vida. La escuela de las competencias que no permite salirse del guión establecido ha acabado por completo con la posibilidad de creación en las aulas.

Es hora de repensar qué entendemos por educación y por Educación Artística y reinterpretar el currículum impuesto, lejano a la realidad del alumnado, que no le representa y no le ofrece la posibilidad de involucrarse en los problemas de la sociedad. Invadamos el espacio público con acciones artísticas que contagien. Fomentemos la participación de las familias y el conjunto de la sociedad a partir de nuestro trabajo. Contemos con artistas jóvenes contemporáneos que trabajen colaborativamente con los centros educativos. Desarrollemos proyectos en contextos educativos reales que generen un cambio también real.

De estas ideas surge el "artivismo" (Mesías-Lema, 2018; Mesías-Lema et al., 2020), un arte comprometido con los procesos creativos de carácter colectivo por un bien común, que se desarrolla en lugares públicos y nace con vocación de sensibilizar a partir de la colaboración y participación acerca de problemáticas de la sociedad como la discriminación o la desigualdad.

Necesitamos actuar con urgencia y resituar la Educación Artística en el lugar que le corresponde, a través de programas financiados que apuesten por la integración de las artes e incidan en el ámbito local y comunitario. Debemos cambiar también la manera de entenderla pues, con la excusa de la "productividad", el "talento" y la "calidad", nos hemos olvidado de la sensibilidad, la creatividad, la igualdad o la responsabilidad social. Una Educación Artística contemporánea, dice el autor, debe ser sensible y humana, preocupándose menos por el yo y más por el nosotros. Aprender a escuchar(nos), a pensar(nos) y a relacionar(nos) es vital para hacer de este un mundo mejor.

Lejos de imponer, el autor provoca y planta la semilla de la curiosidad en el alumnado y en quien tenga en sus manos este libro. Sus palabras muestran esperanza, pero no una revolución utópica futura, sino una activa, presente, decidida, potente y contagiosa.

\section{Referencias}

Agra Pardiñas, M. J. \& Mesías Lema, J..M. (2007). Espacio educativo, Espacio estimulante? Centro Galego de Arte Contemporánea (CGAC).

Mesías Lema, JM. (2011). Autopsia educativa. Museo de Arte Contemporáneo y Energía (AIE), Centro Galego de Artes da Imaxe, Universidade da Coruña.

Mesías-Lema, J. M. (2017). Art Teacher Training: a photo essay. International Journal of Education through Art, 13 (3), 395-404. https://doi.org/10.1386/eta.13.3.395_1

Mesías-Lema, J. M. (2018). Artivismo y compromiso social: transformar la formación del profesorado desde la sensibilidad. Comunicar, 57(26), 19-29. https://doi.org/10.3916/C57-2018-02

Mesías-Lema, J. M., López-Ganet, T. \& Calviño-Santos, G. (2020). Atmospheres: Shattering the architecture to generate another educational discourse in art education. International Journal of Education \& the Arts, 21(6). http://doi.org/10.26209/ijea21n6

Tiffany López-Ganet

Universidad de Granada

tiffany.lopez.ganet@gmail.com 